\title{
Filarial Lymph Edema, Current Status
}

\author{
${ }^{1}$ Dr Avinash Shankar, ${ }^{2}$ Dr Amresh Shankar, ${ }^{3}$ Dr Anuradha Shankar \\ ${ }^{1}$ MBBS(MGIMS);MD(Internal Medicine);DNB(E\&M);PhD, Post graduate in Endocrinology \& \\ Metabolism (AIIMS-Delhi), National Institute Of Health \& Research, Warisaliganj (Nawada), Bihar, \\ 805130 India \\ ${ }^{2}$ BAMS (BRABU); MBA (HA), Bihar State Health Services, Govt of Bihar \\ ${ }^{3}$ BAMS (BRABU), Director, Centre for Research in Indigenous Medicine, Medical Officer, \\ Jharkhand Health Services
}

\begin{abstract}
Filarial lymphedema, an agonizing presentation of Filariasis, un common in area of high water fluoride, supports the clinical evaluation of Sodium fluoride and Lignocain $2 \%$ intradermal injection at the site of lymphedema, causes lysis of adult worm occluding lymphatic system, relieves lymphedema, Bioneurogenes prompt muscular tone and alleviate venous stasis, prompt healing of ulceration and improves immune response.
\end{abstract}

Keywords: Filarial lymphedema, Water fluoride, Occlusion, Venous stasis, Immunity)

\section{INTRODUCTION}

Lymphatic filariasis (LF) is a vector-borne disease of the tropical and subtropical countries ,endemic in eastern India due to infection by filarial worms (Wuchreria bancrofti), which invade the lymphatics of humans initiating pathological changes leading to later filarial disease manifestations ${ }^{1,2}$

Lymphatic filariasis, transmitted by mosquitoes is the commonest cause of lymphedema in endemic countries. Among 120 million infected people in 83 countries, up to 16 million have lymphedema. Microfilariae ingested by mosquitoes grow into infective larvae. These larvae entering humans after infected mosquito bites grow in the lymphatics to adult worms that cause damage to lymphatics resulting in dilatation of lymph vessels ${ }^{3}$

lymphatic damage predisposes to bacterial infection that causes recurrent acute attacks of dermatolymphangio-adenitis in the affected limbs. Bacteria, mainly streptococci gain entry into the lymphatics through 'entry lesions' in skin, like interdigital fungal infections, injuries, eczema or similar causes that disrupt integrity of skin. Attacks of dermato-lymphangio - adenitis aggravates lymphatic damage causing lymphedema, which gets worse with repeated acute attacks. Elephantiasis is a late manifestation of lymphatic filariasis, which apart from limbs may involve genitalia or breasts. $^{4}$

In addition presents with its consequent sequel ${ }^{5,6}$ i.e - elephantiasis and necrosis is increasing progressively in spite of the commonly prescribed Di ethyl carbamazine citrate in dose of $2 \mathrm{mg} / \mathrm{kg}$ every 8 hours which only relieve toxic phase i.e- pyrexial phase but fails to relieve lymph edema 7,8,9 In addition current therapeutic added in its treatment i.e.- Ivermectine also fails to alleviate lymph edema which in turn causes mucin deposit and elephantiasis posing encumbrance even in natural routine activity

In advanced stages of lymphedema the skin is thickened and thrown into folds, often with hypertrichosis, black pigmentation, nodules, warty growth, intertrigo in the webs of toes or chronic non-healing ulcers. The swelling may be so huge and grotesque that the patient is incapacitated requiring help even for personal needs. Fungal infections in the interdigital region and in deep folds are a common finding in advanced lymphedema

Filariasis pathogenesis can be summarized as ${ }^{10}$ 


\section{Filariasis}

(Wuchereria bancrofii)

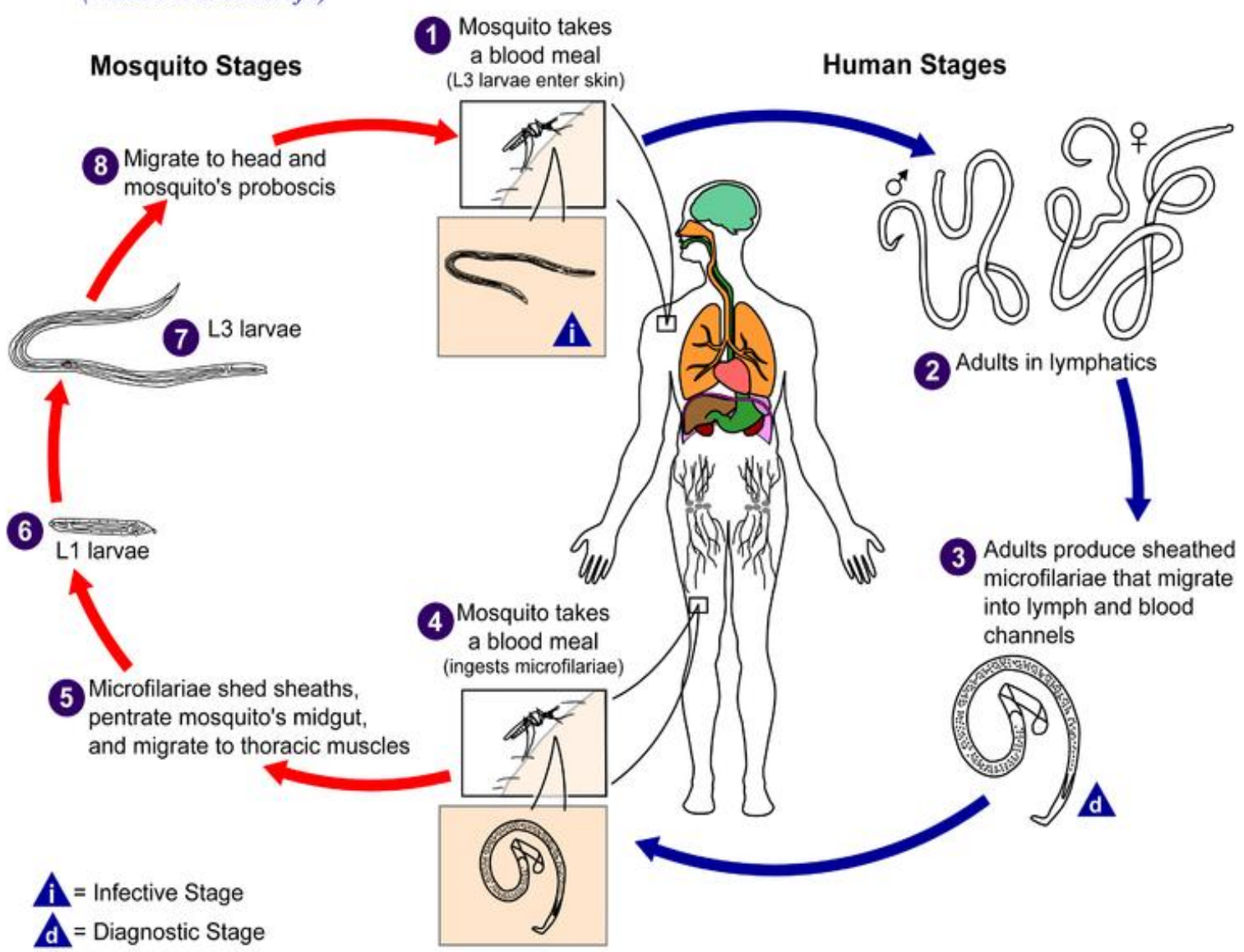

Considering the rare incidence of Filariasis Or Filarial lymph edema in area of high water fluoride content ,prompted use of sodium fluoride subcutaneously so that it is drained to local lymphatic system and cause lysis of the occluding Wuchreria bancrofti and proper draining ensure decline and alleviation of lymph edema, but Sodium fluoride, an irritant may cause intense agonizing pain so adjuncted with local anaesthetic $2 \%$ ligtnocain $1 \mathrm{ml}$ to counter Sodium fluoride irritant effect and ensure slow and sustained release of Sodium fluoride, Hence a study was planned to evaluate the composite in management of Filarial lymph edema for its efficacy and safety profile .

\section{Material \& Methods}

Design of study: Placebo based comparative study

\subsection{Material}

Patients of Lymphatic filariasis attending RA. Hospital \& Research Centre, Warisaliganj during 20042014 were considered for the proposed clinical study.

After due knowledge of the study, creating awareness regarding dietary restriction and proper instruction for the therapeutics patients with associated disease like Diabetes mellitus, persistent non healing chronic ulcer, long standing elephantiasis been excluded.

\subsection{Methods}

Selected patients were duly interrogated for onset of disease, its progress, therapy taken and their response, clinically examined to asses their clinical status and graded as per the status of disease and patients encumbrance, investigated to establish the disease by Prednisolon provocative test or card test, blood sugar, skin scrap examination for any eczematization or fungal super infection ${ }^{11,12,13}$.. Other bio parameters like hematological, hepatic, renal parameters and, thyroid function were also assessed for pre and post therapy comparison to assess safety profile. Girth of lymph edema part is measured to assess the clinical significance of the used therapeutics. 


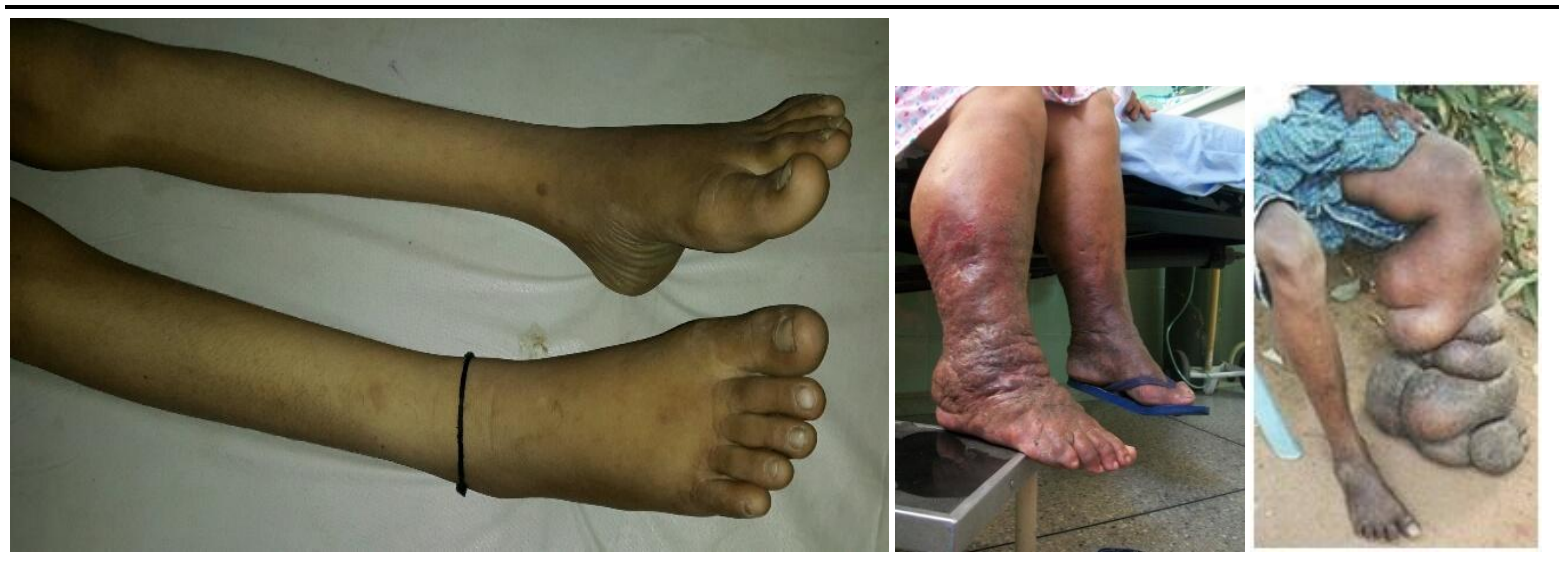

Grade I - Pitting edema, reversible on elevation of the affected limb.

Grade II - Pitting or non-pitting edema, which does not reverse on elevation of the affected limb and there are no skin changes.

Grade III - Non-pitting edema that is not reversible, with thickening of the skin.

Grade IV - Non-pitting edema that is not reversible, with thickening of skin along with nodular or warty excrescences - the stage of elephantiasis.

Selected patients were classified in two groups comprising equal number of patients and wre administered -

Strict dietary restriction helping in propagation of filarial lymph edema in either group patients (Curd, banana, rice, cold beverage, ice chilled water, lemon)

Both group were given Di Ethyl Carbamazine in dose of $2 \mathrm{mg} / \mathrm{kg}$ every 8 hours for 21 days and Tab Ivermectine $0.1 \mathrm{mg} / \mathrm{Kg}$ daily for 10 days, 2 courses on alternate month

Group A:

2 schedule of Inj Sodium Fluoride and Inj Lignocain 2\% $1 \mathrm{ml}$ each as combo every week subcutaneously for 4 weeks

Cap Neurovit (A biogenic neuro facilitator herb composite) daily for 3 months

Group B

Placebo therapy

(Prednisolon provocative test: administration of Prednisolon 5mg ,1/2 tab every 8 hours for 48 hours prior to PS for Microfilaria examination

Card Test: Either with serum or whole blood to asses filarial antibody)

Therapeutic efficacy was graded as -

Grade I: $\quad$ Relief of presenting feature, decline in swelling, attaining normal girth and feature, healing of prevailing necrotic ulcer.

Grade II Relief of presenting feature, mild decline in swelling and healing of necrotic ulcer

Grade III Mild relief, no decline in swelling or edema

\section{ObServation}

Selected patients were of age group 15-50 years with predominance in female ,may be more awareness for encumbrance, the male female composition is 705:778 (Table -1 \& Pie diagram)

Majority 666 were presenting with lower extremity involvement where as 489 patients had involvement of both upper and lower extremity (Bar diagram)

Out of all 29 cases were of illness duration $<1$ yr while 799 were of $>5$ years (Table-2) 
Out of all majority were of lymph edema (846) while 148 patients were with pressure effects i.e. necrotic ulceration associated with elephantiasis (Table -3), as per clinical stage group wise constitution majority patients are of stage II (Table -4), Pre and post therapy status of hematology, hepatic and renal status shows marked improvement (Table-5)

All patients of group A had complete regression of edema symmetrical other counter part but in case of elephantiasis cases though all had regressed lymph edema but not attended as per the counterpart, had complete healing of ulceration with marked regression in lymph edema, but control group failed to show regression in lymph edema, decline in ulceration except few symptomatic relief.

No patients of either group show any further exacerbation during the treatment while No patients of group A had any recurrence or exacerbation or relapse in 3 years of follow up ..

No patients of either group show any drug adversity or alteration in hematological, hepatic and renal parameters or local necrosis at the site of injection.

Patients of lymph edema had grade I response while other had grade II response (T-6, out come of therapy)

Table1. Distribution of patients as per age and sex

\begin{tabular}{|l|l|l|l|}
\hline Age group (in years) & Number of patients & \multicolumn{2}{l|}{} \\
\hline & Male & Female & Total \\
\hline $15-20$ & 124 & 94 & 218 \\
\hline $20-25$ & 78 & 104 & 182 \\
\hline $25-30$ & 109 & 133 & 242 \\
\hline $30-35$ & 72 & 97 & 169 \\
\hline $35-40$ & 79 & 82 & 144 \\
\hline $40-45$ & 111 & 132 & 243 \\
\hline $45-50$ & 149 & 136 & 285 \\
\hline
\end{tabular}

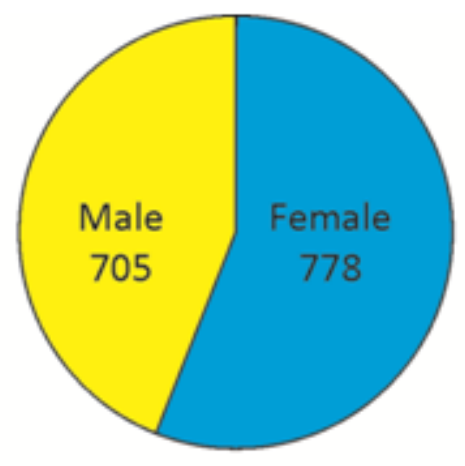

Pie diagram showing male and female preposition

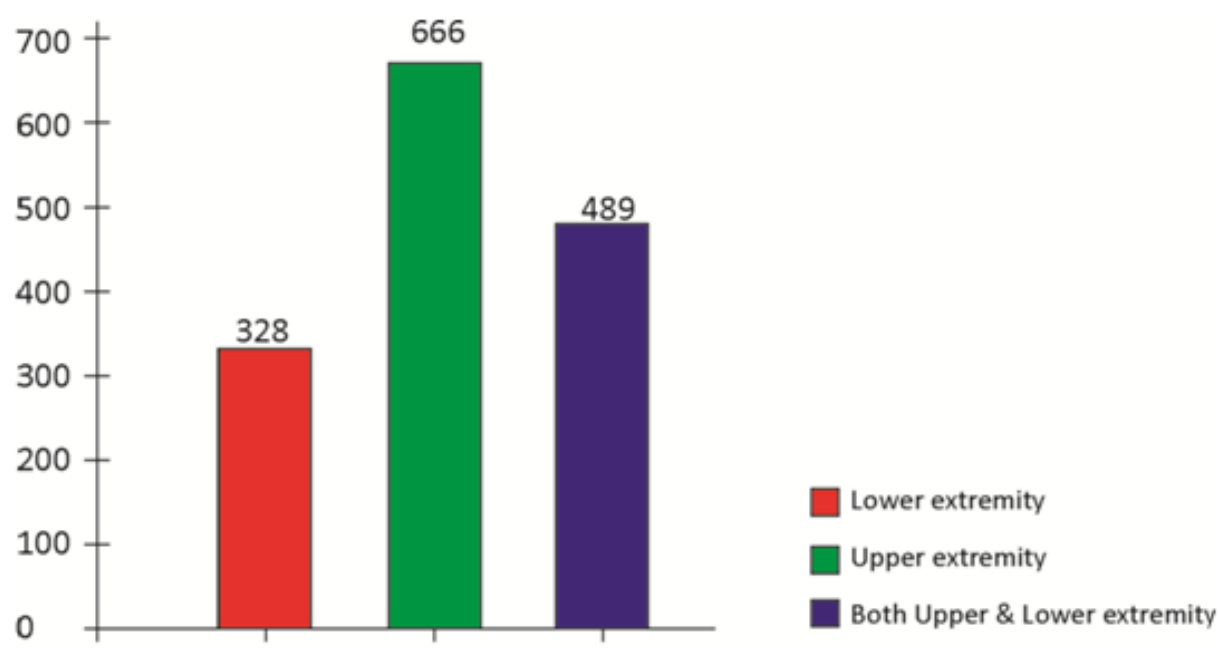

No. of Patients

Bar diagram showing distribution of lymph edema 
Avinash Shankar et al.

Table2. Distribution of patients as per duration of illness

\begin{tabular}{|l|l|}
\hline Duration of illness (in years ) & Number of patients \\
\hline$<1$ & 28 \\
\hline $1-2$ & 103 \\
\hline $2-3$ & 116 \\
\hline $3-4$ & 187 \\
\hline $4-5$ & 250 \\
\hline$>5$ & 799 \\
\hline
\end{tabular}

Table3. Distribution of patients as per disease status

\begin{tabular}{|l|l|}
\hline Particulars & Number of patients \\
\hline Lymph edema & 846 \\
\hline Elephantiasis & 489 \\
\hline Blisterisation or Necrotization & 48 \\
\hline
\end{tabular}

Table4. Group wise distribution of patients as per clinical stage

\begin{tabular}{|l|l|l|l|}
\hline Clinical stage & \multicolumn{2}{|l|}{ Number of patients } & Total \\
\hline & Group A & Group B & \\
\hline Stage I & - & - & - \\
\hline Stage II & 423 & 423 & 846 \\
\hline Stage III & 245 & 244 & 489 \\
\hline Stage IV & 074 & 074 & 148 \\
\hline Total & 742 & 741 & 1483 \\
\hline
\end{tabular}

Table5. Showing pre and post therapy basic biological values

\begin{tabular}{|c|c|c|}
\hline \multirow[t]{2}{*}{ Parameters } & \multicolumn{2}{|c|}{ Number of patients } \\
\hline & Pre therapy & Post therapy \\
\hline $\begin{array}{l}\text { Hematology: } \\
\text { Hemoglobin } \\
<10 \mathrm{gm} \% \\
>10 \mathrm{gm} \%\end{array}$ & $\begin{array}{l}183 \\
1300\end{array}$ & $\begin{array}{l}72 \\
1411\end{array}$ \\
\hline $\begin{array}{l}\text { Hepatic profile : } \\
\text { SGOT } \\
<40 \mathrm{IU} \\
>40 \mathrm{IU} \\
\text { SGPT } \\
<40 \mathrm{IU} \\
>40 \mathrm{IU}\end{array}$ & $\begin{array}{l}1360 \\
123 \\
1360 \\
123\end{array}$ & $\begin{array}{l}1466 \\
17 \\
1466 \\
17\end{array}$ \\
\hline \begin{tabular}{lc}
\multicolumn{2}{l}{ Renal profile } \\
Urine - \\
Albumin & $\begin{array}{c}\text { Present } \\
\text { Absent }\end{array}$ \\
Oxalate & Present \\
& Absent
\end{tabular} & $\begin{array}{l}212 \\
1271 \\
116 \\
1367\end{array}$ & $\begin{array}{l}19 \\
1464 \\
06 \\
1477\end{array}$ \\
\hline $\begin{array}{l}\text { Blood urea } \\
<30 \mathrm{mg} \\
>30 \mathrm{mg}\end{array}$ & $\begin{array}{l}1459 \\
24\end{array}$ & $\begin{array}{l}1483 \\
-\end{array}$ \\
\hline $\begin{array}{l}\text { Serum creatinine } \\
<1.5 \mathrm{mg} \% \\
>1.5 \mathrm{mg} \%\end{array}$ & $\begin{array}{l}1472 \\
11\end{array}$ & $\begin{array}{l}1483 \\
-\end{array}$ \\
\hline
\end{tabular}

Table6. Showing out come of therapy

\begin{tabular}{|l|l|l|}
\hline Particulars & Numbers of patients \\
\hline & Group A & Group B \\
\hline $\begin{array}{l}\text { Marked regression of } \\
\text { Swelling within 8 weeks }\end{array}$ & 742 & 102 \\
\hline $\begin{array}{l}\text { Complete alleviation of } \\
\text { Swelling on completion Of therapy }\end{array}$ & 742 & - \\
\hline Healing of ulceration & All & None \\
\hline Regression of keratinization of skin & All & None \\
\hline $\begin{array}{l}\text { Grades of Clinical out come : } \\
\text { Grade I }\end{array}$ & 443 & - \\
Grade II & 268 & 560 \\
Grade III & 31 & - \\
\hline
\end{tabular}




\section{RESUlT}

Therapeutic regime Tab Di Ethyl Carbamazine $2 \mathrm{mg} / \mathrm{kg}$ every 8 hours for 21 days and Tab Ivermectine $0.1 \mathrm{mg} / \mathrm{kg}$ daily for 10 days , $1^{\text {st }}$ and $3^{\text {rd }}$ month ,inj Sodium Fluoride and Inj Lignocain $2 \%$ intradermally every week in $2^{\text {nd }}$ and 4 th month with Bio neurogen (Cap Neurovit- 1 cap daily orally ) for all the 4 months achieve grade I response in all the cases of lymph edema while other had grade II response without any adversity or recurrence in5 years of vigil follow up.

\section{DISCUSSION}

Filariasis is an endemic disease commonly present with fever with chills and rigor but usually its chronicity prompts very much crippling manifestation i.e.- lymph edema, elephantiasis and necrotic ulceration. Though Di Ethyl Carbamazine widely used for filarial manifestation and these days filarial prevention with albendazol 400mg, Di Ethyl Carbamazine 200mg and Ivermectine $6 \mathrm{mg}$ annually as prophylaxis being used world wide as per WHO guidelines but fails to prevent or alleviate lymph edema or any effect of elephantiasis ${ }^{14}$.

In this study grade I clinical response in all patients of study group without any alteration in hemato,hepatic and renal profile or drug related adversity and recurrence or exacerbation or relapse in 5 yrs of vigil follow up certainly proves worth in management of Filarial lymph edema Or lymphatic filariasis as -

DEC in therapeutic dose ceases acute presentation and help scavenge filarial toxin

Inj Sodium fluoride with lignocain $2 \%$ each $1 \mathrm{ml}$ subcutaneously which ensures painless prick and sustained slow absorption of the Sodium fluoride to the lymphatic on subcutaneous administration, Sodium fluoride prompts lysis of adult worm and releases lymphatic obstruction.

Bioneurogen prompts muscular tone and increase venous drainage, thus helps alleviate necrotic ulceration by relieving venous stasis, improve immune response.

\section{REFERENCES}

[1] World Health Organization. Bridging the Gaps World Health Report. Geneva, Switzerland: WHO; 1995.

[2] Michael E, Bundy DAP, Grenfell BT. Re-assessing the global prevalence and distribution of lymphatic filariasis. Parasitology. 1996;112:409-428. [PubMed]

[3] Pani SP, Yuvaraj J, Vanamail P, Dhanda V, Michael E, Grenfell BT, Bundy DAP. Episodic adenolymphangitis and lymphedema in patients with bancroftian filariasis. Trans Roy Soc Trop Med Hyg. 1995;89:72-74. [PubMed]

[4] Ramaiah KD, Das PK, Michael E, Guyatt H. Economic burden of lymphatic filariasis in India. Parasitol Today. 2000;16:251-253. [PubMed]

[5] Burri H, Loutan L, Kumaraswami V, Vijayasekaran V. Skin changes in chronic lymphatic filariasis. Trans Roy Soc Trop Med Hyg. 1996;90:671-674. [PubMed]

[6] Partono F. The spectrum of disease in lymphatic filariasis. Ciba Found Symp. 1987; 127:15- 31.[PubMed]

[7] Gyapong JO, Kumaraswami V, Biswas G, Ottesen EA. Treatment strategies underpinning the global programme to eliminate lymphatic filariasis. Expert Opin Pharmacother. 2005;6:179 200. [PubMed]

[8] Freedman DO, Bui T, de Alemeida Filho PJ, Braga C, Maia E, Silva MC, Maciel A, Furtado AE. Lymphoscintigraphic assessment of the effect of diethylcarbamazine treatment on lymphatic damage in human bancroftian filariasis. Am J Trop Med Hyg. 1995;52:258-261. [PubMed]

[9] Shenoy RK, Suma TK, Rajan K, Kumaraswami V. Prevention of acute adenolymphangitis in brugian filariasis: comparison of the efficacy of ivermectin and diethylcarbamazine, each combined with local treatment of the affected limb. Ann Trop Med Parasitol. 1998;92:587594. [PubMed]

[10] World Health Organization. Lymphatic filariasis: the disease and its control. WHO Tech Rep Ser. 1992;821 [PubMed] 
[11] Kumaraswami V. The clinical manifestations of Lymphatic Filariasis. In: Nutman TB, editor. Lymphatic Filariasis. London, U.K.: Imperial College Press; 2000. pp. 103-125.

[12] Dreyer G, Noroes J, Figueredo-Silva J, Piessens WF. Pathogenesis of lymphatic disease in bancroftian filariasis. Parasitol Today. 2000;16:544-548. [PubMed]

[13] Pani SP, Lall R. Clinical features, pathogenesis and management of lymphatic filariasis. ICMR Bull. 1998;28:41-51.

[14] Addiss DG, Dreyer G. Treatment of lymphatic filariasis. In: Nutman TB, editor. Lymphatic Filariasis.London, U.K.: Imperial College Press; 2000. pp. 151-199.

[15] Casley-Smith JR. Management of lymphedema in India - A suggested protocol for prevention and treatment; Progress in lymphology. XVII - Proceedings of the 17th Int Congr Lymphol; 1925 September; Chennai, India. 1999. pp. 151-154.

Citation: A. Shankar, "Filarial Lymph Edema, Current Status", International Journal of Clinical Chemistry and Laboratory Medicine (IJCCLM), vol. 3, no. 2, pp. 28-34, 2017. http://dx.doi.org/10.20431/24557153.0302004

Copyright: () 2017 Authors. This is an open-access article distributed under the terms of the Creative Commons Attribution License, which permits unrestricted use, distribution, and reproduction in any medium, provided the original author and source are credited. 